\title{
Sclerosing Rhabdomyosarcoma
}

National Cancer Institute

\section{Source}

National Cancer Institute. Sclerosing Rhabdomyosarcoma. NCI Thesaurus. Code C121655.

An uncommon variant of rhabdomyosarcoma with sclerosing morphology. It usually arises from the limbs. 